\title{
Lifestyle intervention for obesity: a call to transform the clinical care delivery system in Mexico
}

This article was published in the following Dove Press journal: Diabetes, Metabolic Syndrome and Obesity: Targets and Therapy

\section{Rolando Giovanni Díaz-Zavala (iD) \\ Maria del Carmen Candia-Plata $\mathbb{D}^{2}$ \\ Teresita de Jesús Martínez-Contreras (D) Julián Esparza-Romero $\mathbb{D}^{3}$}

'Nutrition Health Promotion Center, Department of Chemical and Biological Sciences, University of Sonora, Hermosillo, Sonora, Mexico; ${ }^{2}$ Department of Medicine and Health Sciences, University of Sonora, Hermosillo, Sonora, Mexico; ${ }^{3}$ Diabetes Research Unit, Department of Public Nutrition and Health, Research Center for Food and Development CIAD, Hermosillo, Sonora, Mexico
Correspondence: Rolando Giovanni Díaz-Zavala

Nutrition Health Promotion Center, Department of Chemical and Biological Sciences, University of Sonora, Blvd. Luis Encinas y Rosales S/N, Hermosillo, Sonora 83000, México. C.P.

Email giovanni.diaz@unison.mx

\begin{abstract}
Obesity and its comorbidities have become the most important public health problems for Latin America. In Mexico obesity has increased dramatically to the point where the government has declared it an epidemiological emergency. The most recent national data showed overweight and obesity affects $72.5 \%$ of adults, or around 56 million Mexicans. Most Mexican adults with obesity are undiagnosed. According to data derived from a national representative survey, only $20 \%$ of adults with BMI $>30 \mathrm{~kg} / \mathrm{m}^{2}$ were diagnosed with obesity by a health provider. Likewise, only $8 \%$ of individuals with obesity had received treatment for obesity. Interventions offered in the Mexican health care delivery system generally consist of traditional consultations with recommendations on diet and exercise, visits are monthly to quarterly, and validated behavior change protocols are not used. Evidence from clinical trials has shown that weight loss with this type of treatment is generally less than $1 \mathrm{~kg}$ per year. In contrast, intensive lifestyle interventions - protocols focusing on achieving changes in diet, physical activity, and moderate weight loss using behavioral strategies with weekly or bi-weekly sessions for the first 3 to 6 months, and a maintenance phase with trained interventionists - as implemented in the Diabetes Prevention Program and the Look AHEAD studies achieved weight loss of 7-9\% at one year. Additionally, translation studies of these interventions to the community and to real-world clinical practice have achieved weight loss of around 4\%. Adaptations of intensive lifestyle interventions have been implemented in the United States, both in clinical practice and in the community, and this type of intervention represents a potential model to combat obesity in Mexico and other Latin American countries. It is essential that primary care providers in Mexico implement clinical practice guidelines based on the best evidence available as discussed here to effectively treat obesity. The authors make recommendations to improve the treatment of obesity in the clinical care delivery system in Mexico using intensive lifestyle interventions.
\end{abstract}

Keywords: nutrition, weight loss, primary care, underdiagnosis, health care providers, diabetes

Obesity and related non-communicable diseases have become the most important public health problems for Latin America. Since 1980, the average BMI in Latin American individuals increased by about $1 \mathrm{~kg} / \mathrm{m}^{2}$ per decade, which is twice as fast as the average global increase ${ }^{1}$ In the case of Mexico, obesity has increased rapidly in recent years among Mexican adults. The prevalence of obesity in women aged 20 to 49 years was $9 \%$ in 1988 , and quadrupled to $35 \%$ in $2012 .^{2}$ The most recent figures in 2016 show that $33.3 \%$ of Mexicans adults are affected by obesity. Further, $72.5 \%$ of the adult population 
are overweight or obese (approximately 56 million). ${ }^{3}$ It is well known that obesity increases the risk of developing chronic non-communicable diseases, such as type 2 diabetes, cancer and cardiovascular disease. ${ }^{4}$ These health problems are the main leading causes of death among adults in Mexico, ${ }^{5}$ and have a heavy toll on the Mexican economy. ${ }^{6}$

\section{Obesity is under-diagnosed in Mexico}

Despite the fact that obesity has been declared the "main modifiable risk factor in the country", ${ }^{7}$ the latest published data on diagnosis from the Mexican health and nutrition survey showed that only $20 \%$ of adults suffering from obesity have been diagnosed by a health care provider. ${ }^{8}$ The under-diagnosis of obesity is well known, even in developed countries such as the United States. ${ }^{9}$ Factors associated with this problem include poor training of health personnel, lack of time for prevention activities, lack of financial incentives to treat obesity, weight stereotyping, and skepticism about the effectiveness of obesity treatment, among others. ${ }^{9,10}$ Block et al observed in a cross-sectional study among internal medicine residents from United States, that although nearly all of them were aware of the consequences of obesity, $61 \%$ were not familiar with the use of BMI for diagnosis, less than $50 \%$ felt qualified to treat obesity, and $31 \%$ reported obesity treatment was futile. ${ }^{11} \mathrm{~A}$ cross-sectional study carried out in a hospital by our research group in northern Mexico in 2007, showed that $79 \%$ of health care providers did not know the range of BMI to diagnose obesity $(80 \%$ primary care physicians, $69 \%$ medicine specialists, $55 \%$ undergraduate medicine interns and $96 \%$ nurses). Further, $78 \%$ of patients evaluated with a BMI $>30 \mathrm{~kg} / \mathrm{m}^{2}$ did not consider themselves as having obesity (Diaz-Zavala et al unpublished data). In 2013, the Mexican Government began the implementation of a national strategy against overweight, obesity and diabetes, which includes actions for health promotion, disease prevention, health regulation, fiscal policy and medical care. ${ }^{12}$ These efforts along with help from civic associations ${ }^{13}$ and recent recommendations by the National Academy of Medicine of Mexico ${ }^{14,15}$ have the potential to substantially improve obesity diagnosis in clinical care. However, to date there is no data available from national representative surveys to show a significant improvement in these figures.

\section{Obesity is under-treated in Mexican adults and the treatments available are not effective}

In relation to obesity management, national-level data revealed that only $8 \%$ of individuals with obesity had received treatment by a health care provider. ${ }^{8}$ However, there is some evidence that a significant proportion of adults may be trying to lose weight, including with strategies that have limited or no scientific support such as herbal products and dietary supplements. ${ }^{16}$ In addition to the low level of treatment, interventions offered in the Mexican clinical care delivery system usually consist of conventional appointments with recommendations on diet and exercise. Visits are not frequent (monthly or quarterly) and validated behavioral change protocols are not used, nor are they contemplated in clinical practice guidelines. ${ }^{17-19}$ Public primary care clinics generally do not have nutritionists, psychologists, or trained personnel in behavioral change; therefore, obesity management relies on medical and nursing personnel. Some primary care clinics and hospitals offer obesity management services by nutritionists or nutrition student interns; however, even with nutritionists, the treatment is given in a traditional fashion without using a behavioral change protocol and with sporadic visits.

Within this context, an important question is whether interventions to treat obesity offered in Mexico's health sector are effective. Tsai and Wadden in 2009 published a systematic review of clinical trials in a primary care setting in the United States. ${ }^{20}$ They identified four brief interventions implemented by primary care physicians with infrequent consultations ( $>1$ month between consultations), similar to what most Mexicans receive. It was noted that participants in each of the four brief intervention groups had a weight loss of $0.1 \mathrm{~kg},{ }^{21} 0.9 \mathrm{~kg},{ }^{22} 1.4 \mathrm{~kg},{ }^{23}$ and $2.3 \mathrm{~kg}^{24}$ in one year. The researchers concluded that the evidence does not support low-to-moderate intensity counseling by physicians to achieve clinically significant weight loss. ${ }^{20}$ Further, Wadden et al conducted a systematic review in 2014, identifying three studies on the effect of an intervention with quarterly or less frequent consultations by primary care physicians. They observed that participants in these low-intensity interventions had a weight loss of only $0.6 \mathrm{~kg}$ to $1.7 \mathrm{~kg}$ in 6 to 24 months. ${ }^{25}$ In the same year Hartman-Boyce et al conducted a systematic review on the effectiveness of interventions with multiple components (diet, exercise, behavioral therapy), implemented by therapists who provided interventions in 
clinical practice on a routine basis, on body weight. They found interventions implemented by primary care teams did not have a significant effect on body weight compared to a control group at 12 months (mean difference of $0.45 \mathrm{~kg}){ }^{26}$ Lastly, a study conducted by our research team where patients with obesity in the control group received monthly conventional appointments by a nutrition student intern (with recommendations on a hypocaloric diet and physical activity) showed that participants increased their body weight by $0.4 \mathrm{~kg}$ in three months. ${ }^{27}$ The studies previously mentioned, including the most recent review, ${ }^{28}$ clearly demonstrate that low-intensity conventional treatment (consultations $>1$ month apart) to which most Mexicans have access, does not have a clinically significant effect on body weight.

\section{Diabetes: a growing problem with poor control}

In 2016, for the first time in history, the Mexican Government declared an epidemiological emergency for two non-infectious health problems: diabetes and obesity. ${ }^{29}$ This was due to the high prevalence of both conditions and the almost 100,000 people who died from diabetes in $2015 .{ }^{29}$ Diabetes doubled nationally from $7.3 \%$ in 2000 to $14.4 \%$ in $2006 .{ }^{30}$ This figure could be higher now, but there is no recent comparative national information. Almost half of individuals that met the criteria for diabetes in 2006 did not know they had it. Meanwhile, $95 \%$ of those who did know, did not have metabolic control of it; ${ }^{30}$ however this figure improved to $75 \%$ in $2012 .^{2}$ Only $15 \%$ of individuals with diagnosed diabetes reported checking their $\mathrm{HbAlc}$ in the previous year. ${ }^{2}$ Both poor diagnosis and poor control of this condition precedes numerous complications, excessive costs, and deterioration in the quality of life.

It was expected that the declaration of an epidemiological emergency of obesity and diabetes in Mexico would improve their diagnosis and control through various strategies, including strengthening the actions of the National Strategy for the Prevention and Control of Overweight, Obesity and Diabetes. ${ }^{12}$ However, the efforts initiated at governmental level, together with academics and institutions, to create a comprehensive evidence-based policy for obesity prevention called the "National Agreement for Healthy Nutrition", was highly opposed by those who saw their interests affected (eg the sugar and food industries), which significantly limited their implementation. ${ }^{31}$ Such opposition even extended to harassing and threatening some researchers and activists who led the effort. $^{32}$ Some researchers have identified possible conflicts of interest in the advisory board of the Mexican Observatory on Noncommunicable Diseases, which plays a key role in directing policy efforts for obesity prevention and control in the National Strategy for Prevention and Control of Overweight, Obesity and Diabetes. ${ }^{33}$ Recently, the health authorities of the new government have recognized this problem. They have also stated that health issues will be disconnected from private initiative and that public health policy will be above private interests. ${ }^{34}$

\section{Opportunities to improve obesity treatment in Mexico}

Obesity and type 2 diabetes could be prevented and controlled more effectively with intensive lifestyle interventions. Such interventions focus on achieving changes in diet, physical activity and moderate weight loss (7-10\%) using a protocol that includes behavioral strategies (stimulus control, self-monitoring, goal setting, social support, etc.), as well as nutrition and physical activity education, with weekly or bi-weekly sessions for the first 3 to 6 months of treatment, and then a maintenance phase monthly or more frequently. ${ }^{35-37}$ Since 2002, evaluations of the Diabetes Prevention Program (DPP) ${ }^{38}$ have shown that it is possible to achieve moderate weight loss (7\% at 1 year and about $4 \%$ at 4 years) with this type of program, and prevent 6 out of 10 cases of type 2 diabetes in individuals at risk. Subsequently, the Look AHEAD study, a multicenter randomized clinical trial, showed that individuals with obesity and type 2 diabetes who participated in an intensive lifestyle intervention (similar to DPP) had positive results in weight control in the short ( 1 year, $-8.5 \%$ vs $-0.6 \%$ control group), medium ( 4 years, $-4.4 \%$ vs $-0.7 \%$ ) and long term ( 8 years, $-4.7 \%$ vs $-2.1 \%$ ). ${ }^{39}$ Concomitant to weight loss, participants in the intensive lifestyle intervention showed numerous health benefits, such as significant improvement in their cardiorespiratory condition, body composition, blood glucose and lipids, blood pressure, systemic inflammation levels, liver fat, sexual function and quality of life, as well as a reduction in sleep apnea, urinary incontinence and depression symptoms. ${ }^{40}$ There was no effect on cardiovascular mortality, which was the primary outcome of the study, $^{41}$ however, a secondary analysis including only the intensive lifestyle intervention participants who achieved a weight loss greater than $10 \%$ did show a significant effect. ${ }^{42}$ A description of the lifestyle protocols for the DPP, Look 
AHEAD and the Mexican adaptation of the DPP for obesity programs are shown in Table 1.

The mandatory question is, why, if there is evidence that traditional treatments are not effective for obesity and the prevention/control of diabetes, does this not translate into changes in clinical practice in Mexico? The lack of transfer of scientific evidence into clinical practice is not a problem confined to Mexico, but it is becoming more and more recognized. ${ }^{45}$ There is a great amount of valuable information from controlled clinical trials (translational research phase 1); however, the dissemination of findings from clinical studies to real-world clinical practice (translational research phase 2) still represents a challenge. ${ }^{45}$

In this context, it can be stated that there is sufficient evidence that the transfer of intensive lifestyle interventions such as the DPP protocol for obesity management and diabetes prevention in different scenarios (community centers, recreation centers, churches and health centers) under real-world conditions can achieve significant weight loss (4\%). ${ }^{27,46}$ This evidence includes a systematic review and meta-analysis of 28 US-based studies ${ }^{46}$ and a pilot study in Mexico. ${ }^{27}$ Additionally, the DPP protocol has been shown to be cost-effective in people at high risk for diabetes, ${ }^{47}$ and the implementation of the DPP in the community through the Young Men's Christian Association (non-governmental organization) in the Unites States has shown the program to be both effective and cost-effective. ${ }^{48,49}$ Given the evidence of effectiveness of the DPP, including in translation studies, the National Diabetes Prevention Program of the Centers for Disease Control and Prevention (CDC) was approved in 2010 by the Congress of United States as a frame of reference to prevent diabetes. ${ }^{50}$ The $\mathrm{CDC}$ through the National Diabetes Prevention Program supports organizations in all 50 US States and the District of Columbia to provide intensive lifestyle interventions to prevent diabetes in high-risk populations. ${ }^{51}$ This program is provided in group mode by a trained lifestyle change facilitator using a protocol approved by the CDC that can be in person, online or mixed. ${ }^{49,52}$ Through the provision of funds for public health departments, the CDC promotes awareness about prediabetes, and the National Diabetes Prevention Program encourages screening, laboratory tests, and referrals to intensive lifestyle interventions.

Currently, intensive lifestyle interventions are considered the gold standard for the management of obesity in the United States. ${ }^{53}$ The most recent report by the US Preventive Task Force in 2018 recommends clinicians to offer or refer adults with obesity to intensive, multicomponent behavioral interventions, ie intensive lifestyle interventions. ${ }^{54}$ Since 2011, the Centers for Medicare and Medicaid Services began reimbursing physicians who offer this type of program to their patients with obesity, based on the evidence found by the US Preventive Services Task Force. ${ }^{55}$ In fact, the first results of this program are already emerging. Treviño et al in a retrospective analysis with 643 patients, found that participants who attended less than 4 sessions did not lose weight, those who attended 4 to 8 sessions had a reduction of $1.1 \mathrm{~kg}$, and those who attended more than 8 sessions lost $3.7 \mathrm{~kg}$. The majority of participants in the study were Hispanic, and clinics were located in low income areas, which may have negatively influenced results. ${ }^{56}$ In the UK, another promising demonstration of effectiveness in treating obesity in routine primary care is the Counterweight Program. ${ }^{57}$ This program was implemented in the UK by practice nurses who were trained and mentored by registered dietitians with specialist training in obesity management. The program includes nutrition education and behavioral strategies, consists of 6 consultations the first 3 months and then quarterly the rest of the year. The participants who completed the 12 months $(43 \%)$ reduced their body weight by $3 \mathrm{~kg}$, and the program has also been shown to be cost-effective. ${ }^{58}$ The above evidence supports intensive lifestyle interventions as a potential model for combating obesity and diabetes in Mexico.

\section{Remaining challenges for Mexico. What is the current state of knowledge and attitude of health care providers in Mexico?}

In the authors' opinion, further research is needed to determine the knowledge and attitude of health care providers in Mexico, including in the public health care system. Important questions include: How many know how to diagnose obesity? How many believe obesity can be treated effectively? How many have the necessary skills to treat obesity (dietary and physical activity counseling, use of behavior change strategies)? How many refer their patients to receive treatment? How many have effective programs to which to refer their patients? How many health care providers would like to actively collaborate in the treatment of obesity? How many health care providers would be willing to receive training? The answers to these questions would help inform the implementation of effective interventions into routine practice. If we do not 


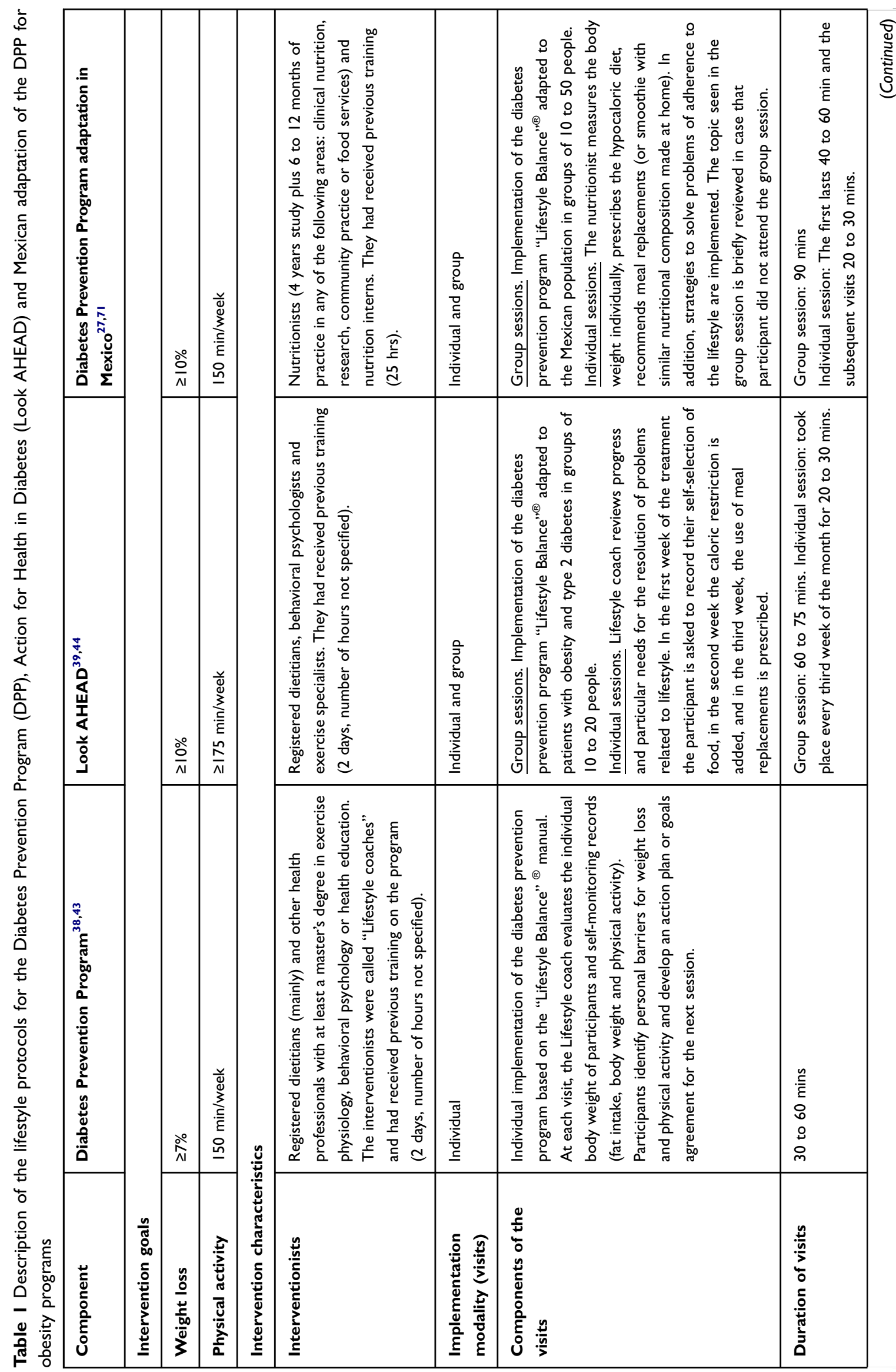




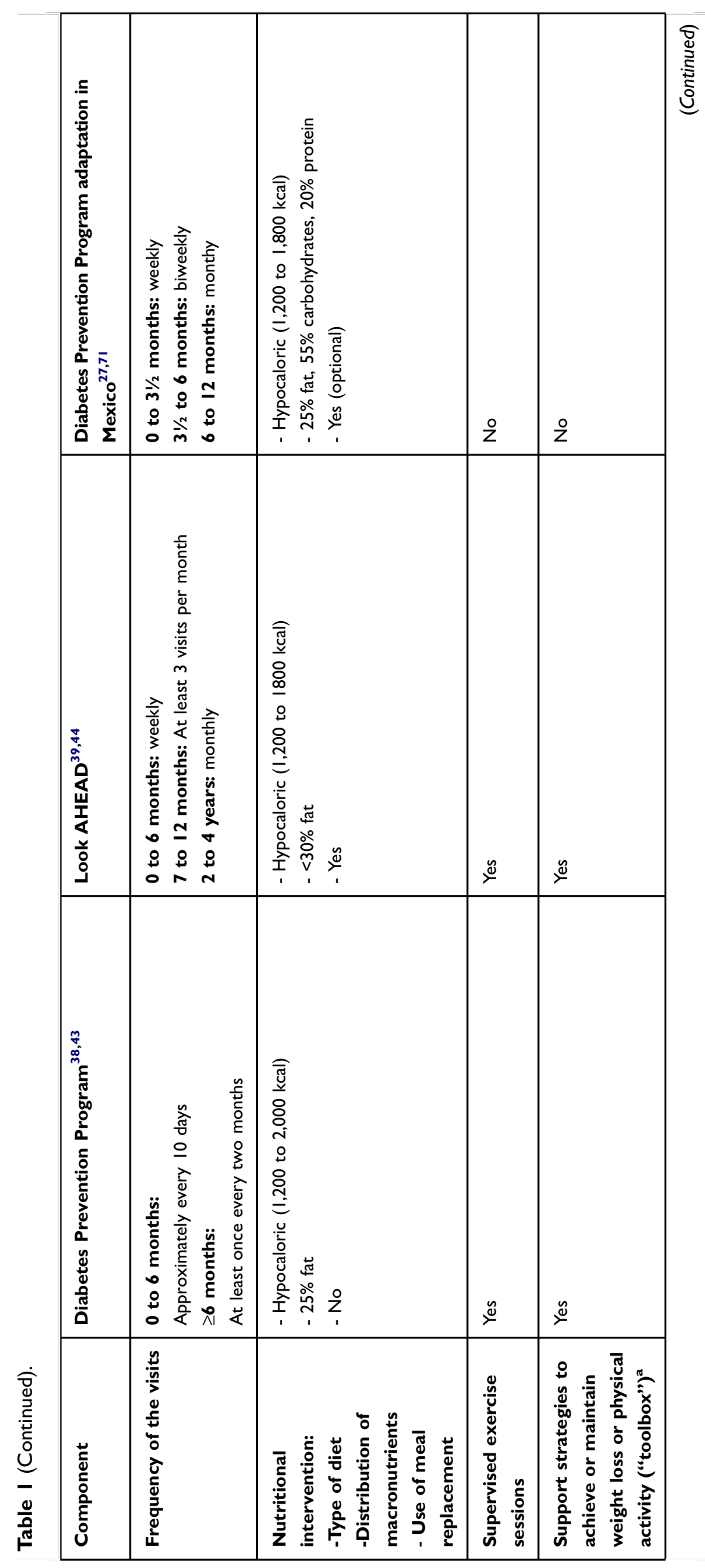




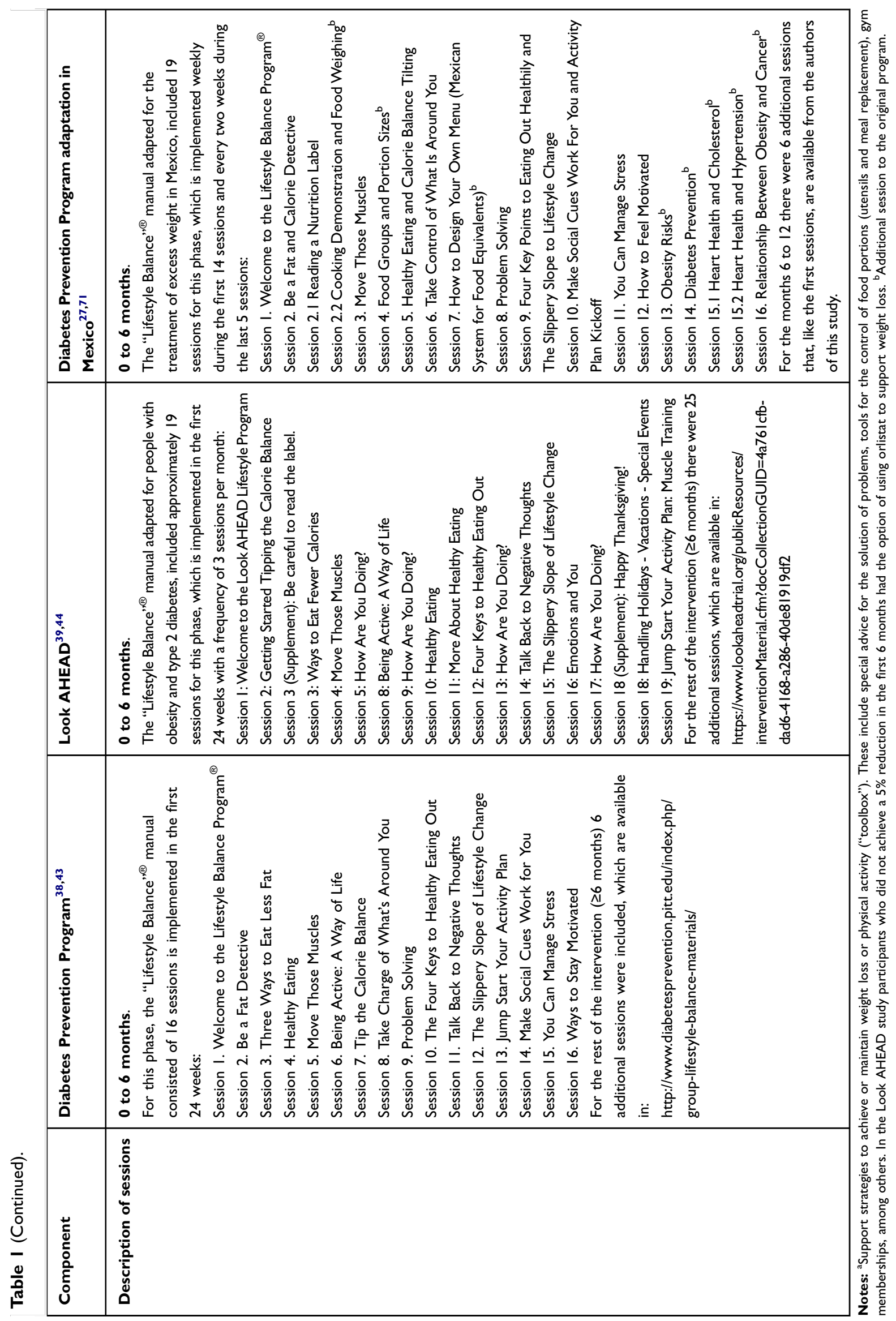


make real efforts to answer these questions, especially in the primary care setting, it will be difficult to achieve substantial progress in the areas of obesity treatment and diabetes prevention in México.

\section{Change the paradigm of the traditional consultation}

If we consider the intensive lifestyle interventions offered in the Diabetes Prevention Program (DPP) and the Look AHEAD studies as an exemplar, offering these programs requires a change of mentality and a restructuring of the traditional treatment model, as well as important changes to public policies in Mexico. First, health personnel must be made aware that there are effective evidence-based programs for obesity management and diabetes prevention, and that they could have access to these types of programs to which to refer their patients. They may also need to receive more nutrition education, ${ }^{59,60}$ training in behavioral change strategies, ${ }^{61}$ physical activity counseling, and intensive lifestyle intervention programs. A crosssectional study conducted in the US showed that only $14 \%$ of resident physicians believe they are adequately trained to provide nutritional counseling. ${ }^{62}$ Another aspect would be contemplating changes to the curriculum of schools of medicine and nursing to avoid the need to correct these problems through continuing medical education. A survey involving more than 100 accredited US medical schools revealed students received less than $20 \mathrm{hrs}$ of nutrition education during their professional training, only 1 in 4 schools had a nutrition course, and only $27 \%$ of schools received the minimum nutrition education $(25 \mathrm{hrs})$ as proposed by the Academy of Sciences. ${ }^{63}$

While clinicians are in some way part of the obesity problem and its poor combat, they also have the potential to be key contributors to the solution. Therefore, they should consider that traditional clinical tools for obesity management are not sufficient. Due to the epidemiological burden of obesity in Mexico, it is necessary to supplement traditional clinical strategies with evidence-based programs that have shown good results.

\section{It is necessary to have access to a multidisciplinary approach and other potential strategies for the management of obesity}

It will be important to examine the possibility of incorporating other key health professionals trained in the implementation of the protocols used in the DPP and Look AHEAD study, such as nutritionists, behavioral psychologists and experts in physical activity. ${ }^{40,43}$ Some studies suggest nutritionists obtain better results in weight control of patients with and without diabetes compared to other health care providers. ${ }^{64,65}$ However, in public primary care clinics in Mexico there are few nutritionists employed in comparison to nurses or doctors (there are 10,000 doctors for every 3 nutritionists). ${ }^{14}$ However, it may be that the type of intervention to be implemented is more important than who implements it. For example, when nutrition interns used the DPP protocol for management of obesity in the primary care setting, participants lost $4.7 \mathrm{~kg}$ in three months vs an increase of $0.4 \mathrm{~kg}$ if provided with monthly traditional consultations. Sixty-two per cent of the DPP group participants had more than $5 \%$ decrease in body weight vs zero per cent in the traditional consultation group. ${ }^{27}$ The same phenomenon was observed when Delahanty and colleagues evaluated the translation of the Look AHEAD study into a primary care clinic in the United States. When nutritionists implemented this high-intensive lifestyle intervention (similar to the DPP protocol), patients lost $6.7 \mathrm{~kg}$ compared to $2.1 \mathrm{~kg}$ when using traditional consultations, which were also given by nutritionists. ${ }^{66}$ In fact, there is evidence that even secular lifestyle-change educators could have positive results in weight control if they apply the DPP protocol. ${ }^{46}$

Another area of great potential is the application of remote technology for obesity management. For example, a study conducted in the primary care setting, showed that an adaptation of the DPP protocol by means of a DVD during the first 3 months of treatment, followed by a maintenance phase with biweekly messages via e-mail and the use of a website, had positive results up to 15 months (-4.5 kg vs -2.4 control group). ${ }^{67}$ Meanwhile, Appel and colleagues had similar findings $(-4.6 \mathrm{~kg}$ vs $-0.8 \mathrm{~kg}$ control group) after 2 years of intervention in primary care, but using phone calls instead of a DVD in the intensive phase of the intervention (12 phone calls weekly and then monthly), as well as the support of a website. ${ }^{68}$ Finally, referral to commercial programs could be another opportunity. Ahern et al recently found that primary care referral to a commercial intensive lifestyle intervention program (Weight Watchers) for 52 or 12 weeks resulted in significant improvement in weight loss at 12 months $(6.76 \mathrm{~kg}$ and $4.75 \mathrm{~kg}$, respectively) vs a brief self-help intervention $(3.26 \mathrm{~kg}) .{ }^{69}$ A more detailed description of these intervention studies can be found in Table 2 . 


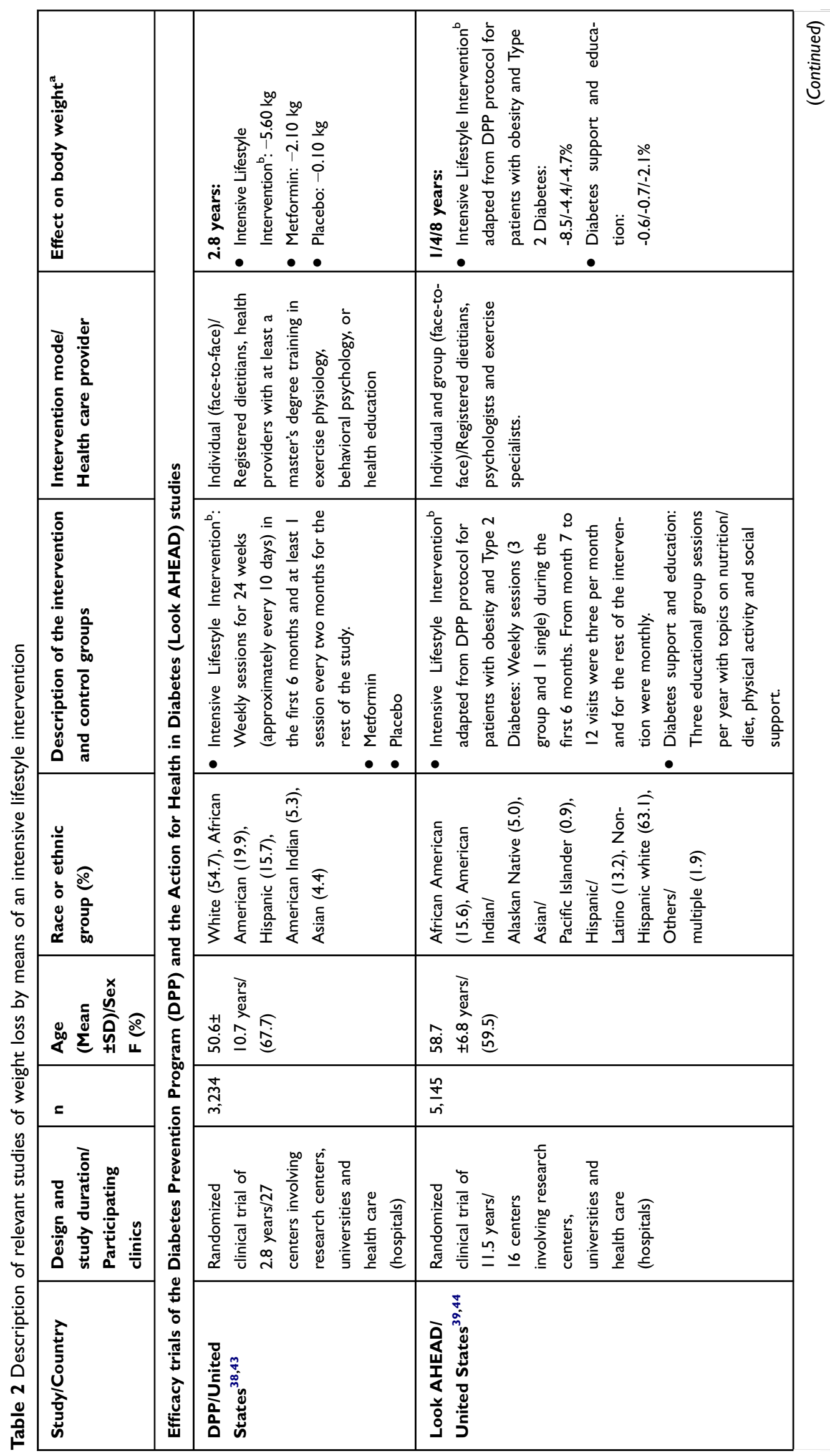




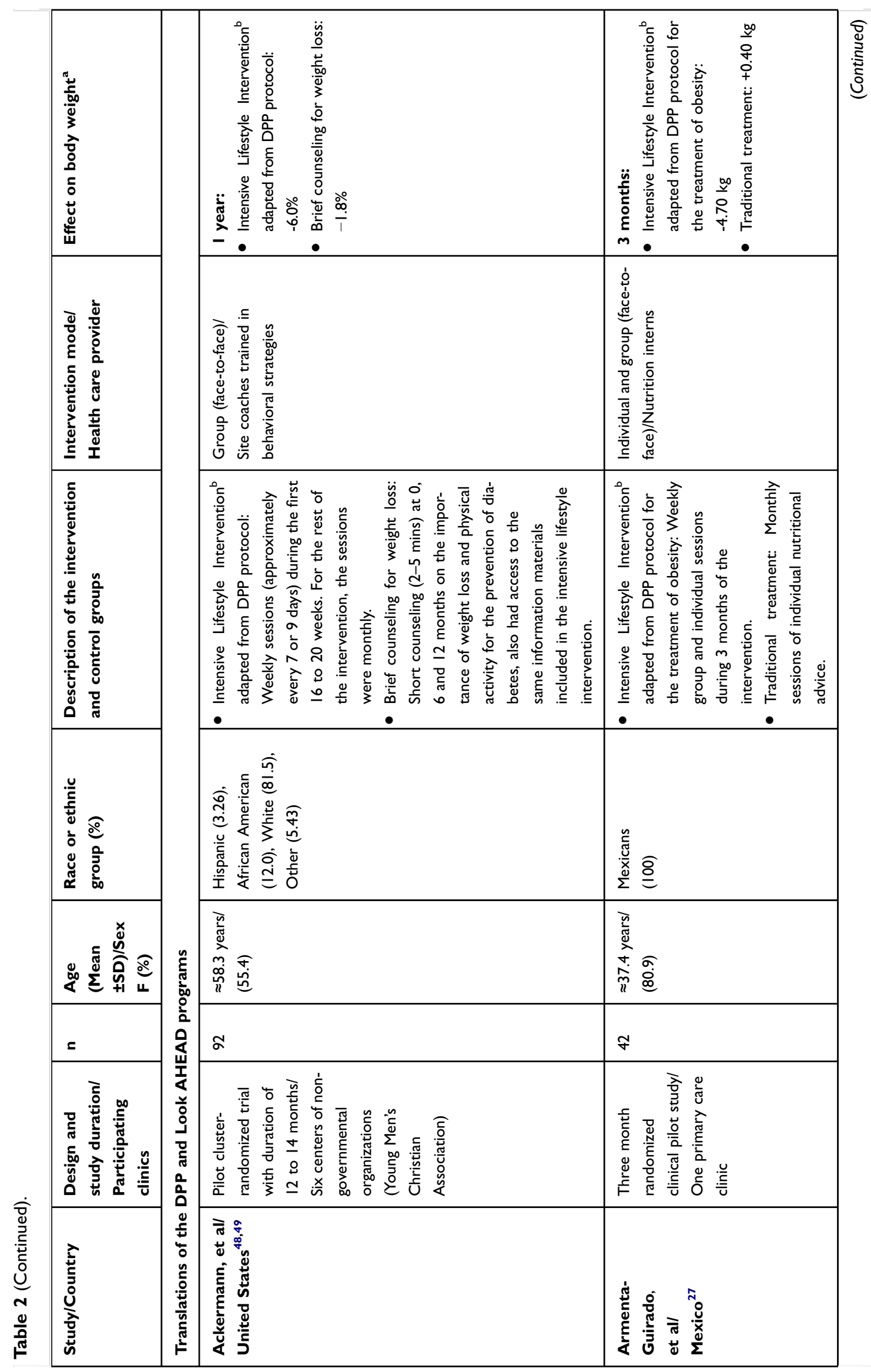




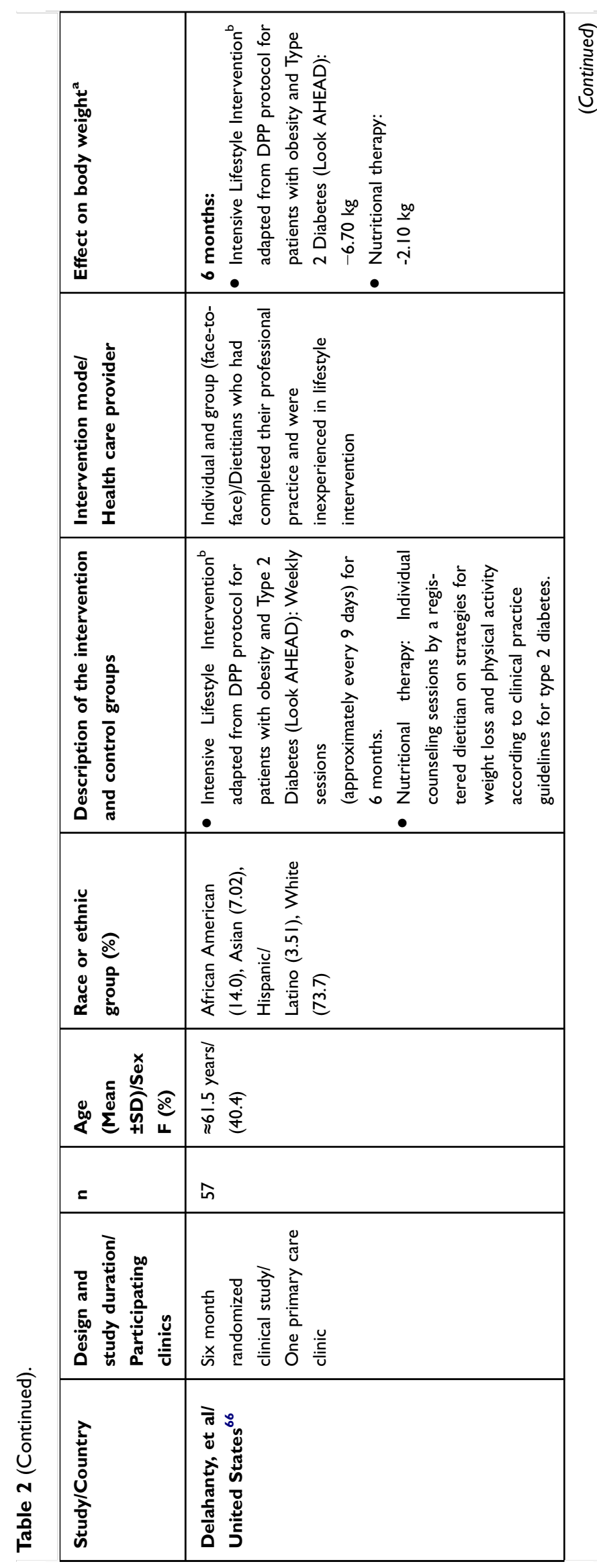




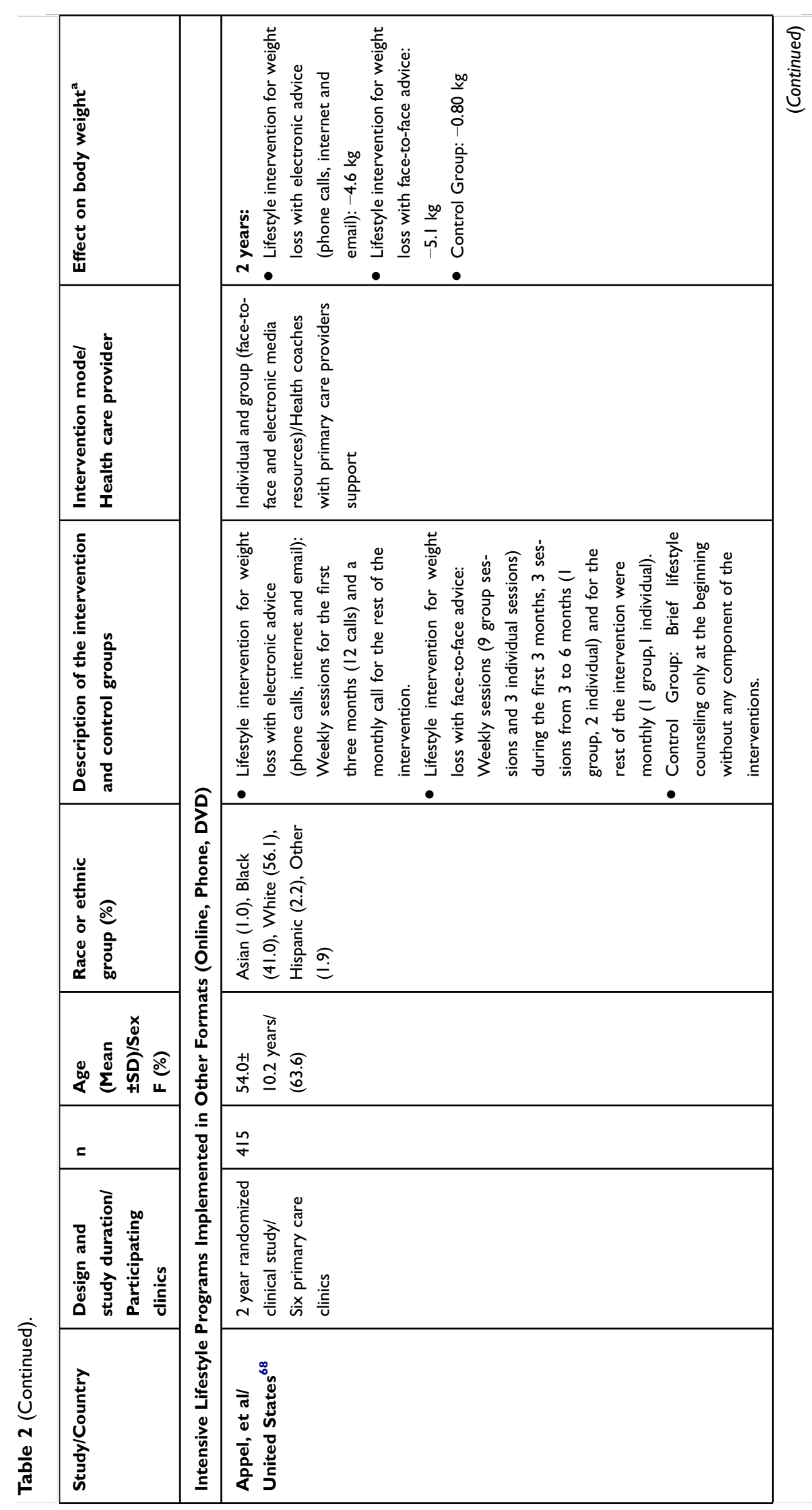




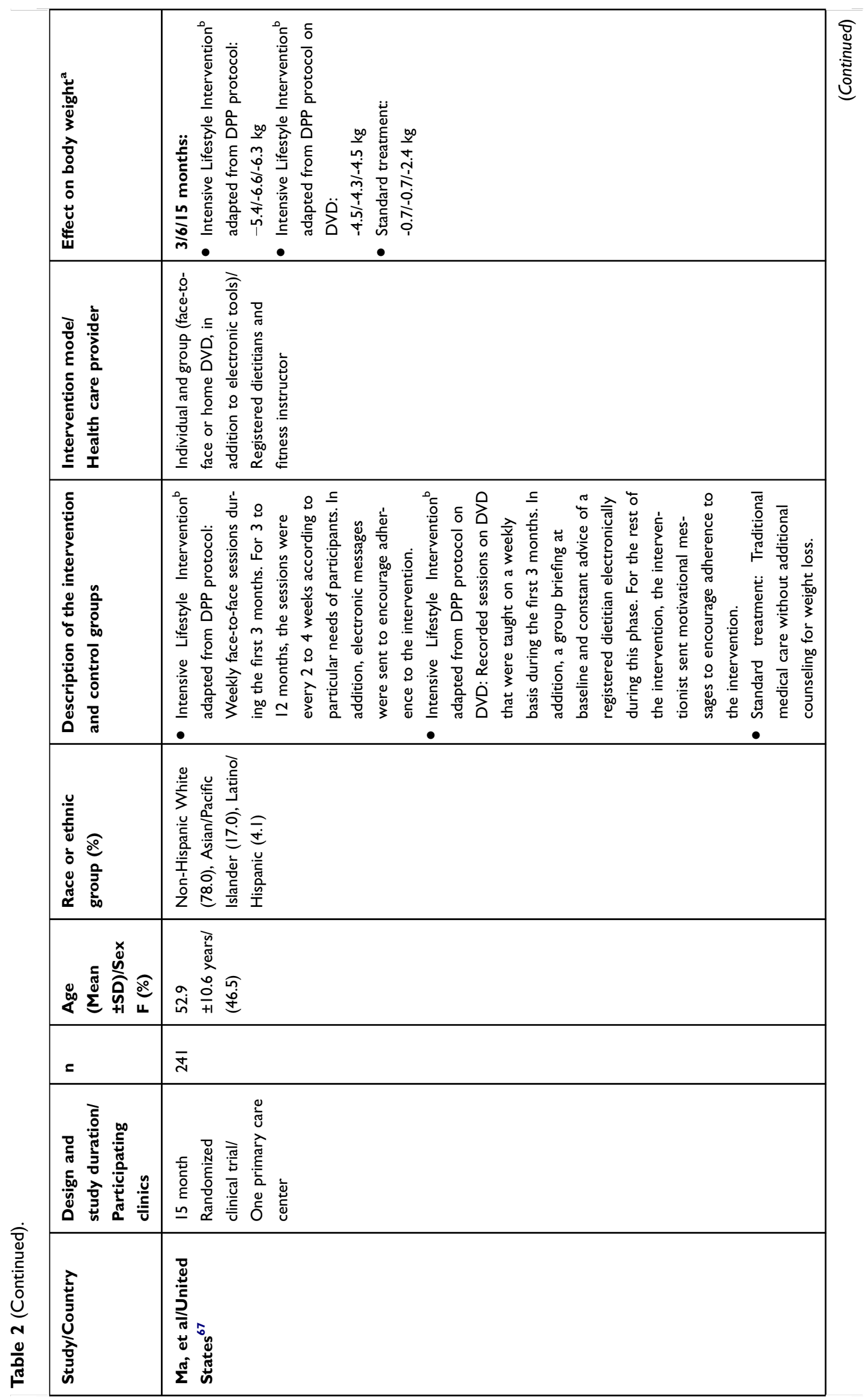




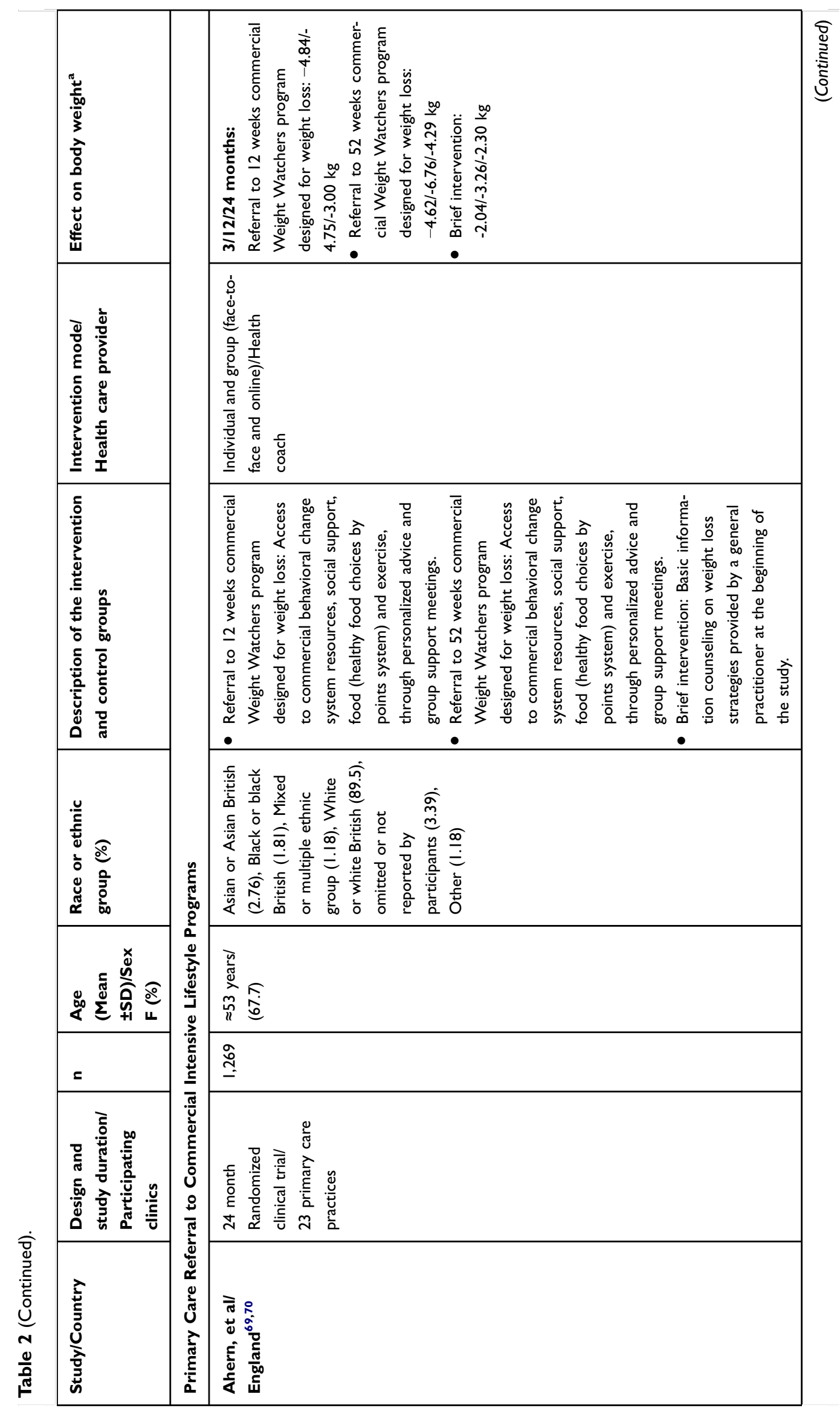




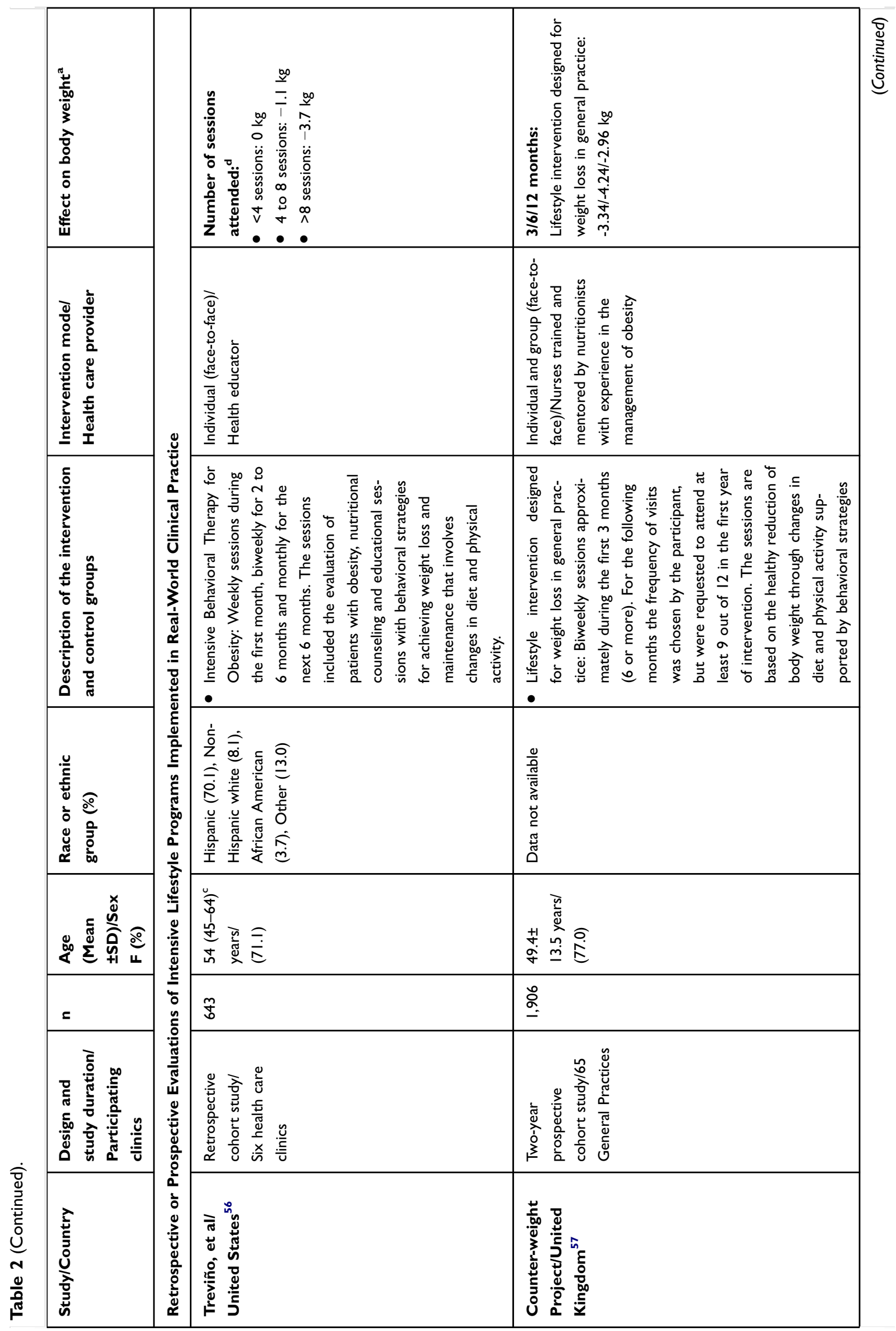




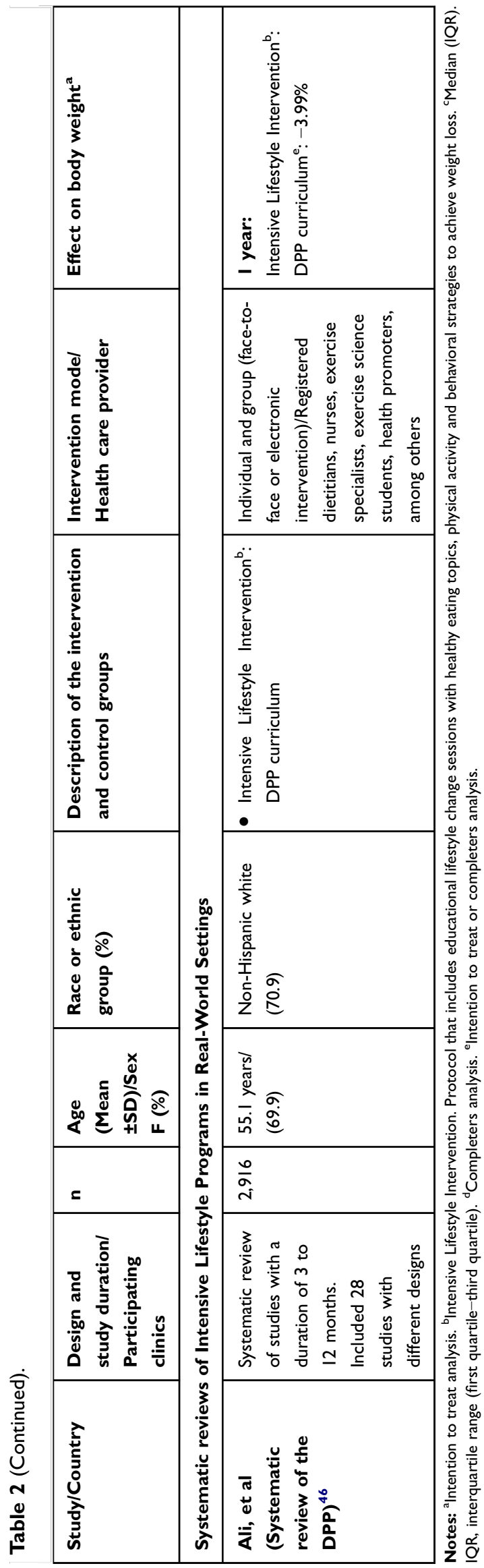

\section{Need for research in México and multiple efforts at different levels to combat obesity}

It is important to note that much of the work discussed in this review was conducted in the US and other developed countries. Studies evaluating the translation of obesity treatments into clinical settings in Mexico and Latin American countries are urgently needed. Our research group will soon have results of the translation of the DPP in five clinics in the northwest of the country ${ }^{71}$ as well as results of the implementation of the online DPP protocol (Clinical Trials Register: NCT03629301). Another fundamental key to improving obesity management in Mexico, will be to develop evidence-based clinical practice guidelines with the collaboration of international experts. If developed countries have considered intensive lifestyle interventions, as defined here, as the gold standard for the management of obesity, it is necessary to discuss whether these interventions should also be the standard for Mexico. Considering the significant problems of obesity and diabetes in Mexico, we should aim to have a program like the US National Diabetes Prevention Program; however, it is unknown if such interventions would have the same impact on our population in terms of weight loss and diabetes prevention.

It is clear that clinical interventions will not solve the obesity problem by themselves, but neither can environmental strategies (regulation, etc.) achieve the calorie deficit needed to treat patients with existing obesity. ${ }^{61}$ We will certainly require multiple efforts at multiple levels -socioecological approaches - to fight obesity and related comorbidities. In this sense, policies outside of the clinical sector have shown positive results in the fight against obesity in México, such as the excise tax on sugar sweetened beverages, ${ }^{72}$ among other promising proposals. ${ }^{73,74}$

\section{Recommendations to improve the lifestyle treatment of obesity in the clinical care delivery system in Mexico}

The National Academy of Medicine of Mexico has recently published a position paper which includes recommendations at multiple levels to improve the prevention and management of obesity. ${ }^{73}$ In Table 3 we give general recommendations to improve the lifestyle treatment of obesity in the clinical care delivery system in Mexico. 
Table 3 General recommendations to improve the treatment of obesity in the clinical care delivery system in Mexico

\begin{tabular}{|l|l|}
\hline I. & Recommendations \\
\hline $\begin{array}{l}\text { Update the Mexican clinical practice guidelines with the collaboration of national experts in obesity management, government health } \\
\text { authorities and international experts. It is recommended that the Diabetes Prevention Program (DPP) protocol be used as the program to } \\
\text { promote lifestyle change considering the availability of materials for its application and the evidence of efficacy and effectiveness on body } \\
\text { weight of adults with obesity. }\end{array}$ \\
\hline 2. & $\begin{array}{l}\text { These guidelines should define the role of each health care provider. They should also clearly describe dietary management, physical activity, } \\
\text { behavioral strategies, frequency of consultations (with broad flexibility according to needs: face-to-face, online, telephone, group, individual), } \\
\text { and follow-up visits, pharmacotherapy and bariatric surgery. Important topics should also be included, such as stigmatization and obesity, how } \\
\text { to initiate a conversation about weight, weight regain, among others. }\end{array}$ \\
\hline 3. & $\begin{array}{l}\text { The primary care setting should have, as far as possible, interdisciplinary teams (including nutritionists or psychologists skilled in behavioral } \\
\text { change) and the basic infrastructure for the diagnosis and treatment of obesity. }\end{array}$ \\
\hline 4. & $\begin{array}{l}\text { Train primary health care providers in these clinical practice guidelines, establish mechanisms of evaluation and feedback to achieve their } \\
\text { implementation. Also establish mechanisms to reward and recognize trained providers, as well as clinics with positive results. }\end{array}$ \\
\hline 5. & $\begin{array}{l}\text { Conduct a pilot study of this project in a municipality or state, evaluate the results and make appropriate adjustments if needed. Once there } \\
\text { are positive results, disseminate it on a larger scale and evaluate the effectiveness of the program. }\end{array}$ \\
\hline
\end{tabular}

The health authorities of the new government have a unique opportunity to take advantage of the efforts of many researchers and the Mexican society to fight against obesity and chronic degenerative diseases. Only time will tell if this opportunity was achieved or if it was another story of failed good intentions.

\section{Acknowledgment}

We thank Rocio Ayala for her technical support on English editing in the first draft of the manuscript. Diaz-Zavala has received support from the University of Sonora, PRODEP Programa para el Desarrollo Profesional Docente [Professional Development Program for Professors] (103.5/ 13/8926) and the IAEA [International Atomic Energy Agency] (16397/R0) for the funding of previous studies in the area. PRODEP paid the cost of publishing the article.

\section{Disclosure}

RGDZ and TJMC are nutritionists and provide training courses on intensive lifestyle change programs to health care providers, where the University of Sonora receives payment for these courses. The authors do not receive any direct payment for it, but they have benefited with part of these funds for research purposes. Additionally, the Nutritional Health Promotion Center provides the protocol of the Diabetes Prevention Program to the community at a cost recovery fee. The authors report no other conflicts of interest in this work.

\section{References}

1. The Lancet Diabetes. Endocrinology. Obesity prevention in Latin America: now is the time. Lancet Diabetes Endocrinol. 2014;2 (4):263. doi:10.1016/S2213-8587(14)70079-8.

2. Gutiérrez J, Rivera-Dommarco J, Shamah-Levy T, et al. Encuesta Nacional de Salud y Nutrición 2012. Resultados Nacionales. Cuernavaca, México: Instituto Nacional de Salud Pública (MX); 2012.

3. Instituto Nacional de Salud Pública. Encuesta Nacional de Salud y Nutrición de Medio Camino 2016. México: Informe Final de Resultados; 2016.

4. Bray G, Kim KK, Wilding JPH, World Obesity Federation. Obesity: a chronic relapsing progressive disease process. A position statement of the world obesity federation. Obes Rev. 2017;18(7):715-723. doi:10.1111/obr.12551.

5. Soto-Estrada G, Moreno-Altamirano L, Pahua-Díaz D. Panorama epidemiológico de México, principales causas de morbilidad y mortalidad. Rev Fac Med Mex. 2016;59:8-22.

6. Rtveladze K, Marsh T, Barquera S, et al. Obesity prevalence in Mexico: impact on health and economic burden. Public Health Nutr. 2014;17:233-239. doi:10.1017/S1368980013000086

7. Barquera S, Campos-Nonato I, Hernández-Barrera L, Pedroza A, Rivera-Dommarco JA. Prevalencia de obesidad en adultos mexicanos, 2000-2012. Salud Publica Mex. 2013;55(2):S151-S160.

8. Pérez-Salgado D, Valdés Flores J, Janssen I, Ortiz-Hernández L. Diagnosis and treatment of obesity among Mexican adults. Obes Facts. 2012;5(6):937-946. doi:10.1159/000346325

9. Ma J, Xiao L, Stafford RS. Underdiagnosis of obesity in adults in US outpatient settings. Arch Intern Med. 2009;169(3):313-314. doi:10.1001/archinternmed.2008.582

10. Lyznicki JM, Young DC, Riggs JA, Davis RM. Council on scientific affairs, American medical association. Obesity: assessment and management in primary care. Am Fam Physician. 2001;63(11):2185-2196.

11. Block JP, DeSalvo KB, Fisher WP. Are physicians equipped to address the obesity epidemic? Knowledge and attitudes of internal medicine residents. Prev Med. 2003;36(6):669-675.

12. Centro Nacional de Programas Preventivos y Control de Enfermedades. Estrategia nacional para la prevención y el control del sobrepeso, la obesidad y la diabetes. México: IEPSA; 2013. 
13. Instituto Carlos Slim de la Salud [homepage on the Internet]. Medición Integrada para la Detección Oportuna (MIDO). México: Salud Fundación Carlos Slim; 2018. Available from: https://salud. carlosslim.org/casalud/mido-medicion-integrada-para-la-deteccionoportuna/. Accessed March 08, 2019.

14. Aguilar-Salinas C, Sevilla-González M. Atención primaria. Modelo de control y atención a la salud. In: Rivera-Dommarco JA, Colchero MA, Fuentes ML, editors. La obesidad en México. Estado de la política pública y recomendaciones para su prevención y control. Cuernavaca: Instituo Nacional de Salud Pública; 2018:241-258.

15. Rivera-Dommarco JA, Colchero MA, Fuentes ML, et al. Postura. Recomendaciones para una política de estado para la prevención y control de la obesidad en México en el periodo 2018-2024. In: Rivera-Dommarco JA, Colchero MA, Fuentes ML, et al. editors. $L a$ obesidad en México. Estado de la política pública y recomendaciones para su prevención y control. Cuernavaca: Instituto Nacional de Salud Pública; 2018:15-30.

16. DiBonaventura MD, Meincke H, Le Lay A, Fournier J, Bakker E, Ehrenreich A. Obesity in Mexico: prevalence, comorbidities, associations with patient outcomes, and treatment experiences. Diabetes Metab Syndr Obes. 2017;11:1-10. doi:10.2147/DMSO.S129247

17. Centro Nacional de Excelencia Tecnológica en Salud. Diagnóstico y tratamiento del sobrepeso y la obesidad exógena. México; CENETEC; 2012.

18. NORMA Oficial Mexicana NOM-008-SSA3-2017, para el tratamiento integral del sobrepeso y la obesidad. México: Secretaría de Gobernación; 2018.

19. Diagnóstico y tratamiento del sobrepeso y obesidad exógena. Guía de Evidencias y Recomendaciones: Guía de Práctica Clínica. México: CENETEC; 2018.

20. Tsai AG, Wadden TA. Treatment of obesity in primary care practice in the United States: a systematic review. J Gen Intern Med. 2009;24 (9):1073-1079. doi:10.1007/s11606-009-1042-5

21. Christian JG, Bessesen DH, Byers TE, Christian KK, Goldstein MG, Bock BC. Clinic-based support to help overweight patients with type 2 diabetes increase physical activity and lose weight. Arch Inter Med. 2008;168(2):141-146. doi:10.1001/archinternmed.2007.13

22. Cohen MD, D'Amico F, Merenstein JH. Weight reduction in obese hypertensive patients. Fam Med. 1991;23(1):25-28.

23. Martin PD, Dutton GR, Rhode PC, Horswell RL, Ryan DH, Brantley PJ. Weight loss maintenance following a primary care intervention for low-income minority women. Obesity (Silver Spring). 2008;16 (11):2462-2467. doi:10.1038/oby.2008.399

24. Ockene IS, Hebert JR, Ockene JK, et al. Effect of physician-delivered nutrition counseling training and an office-support program on saturated fat intake, weight, and serum lipid measurements in a hyperlipidemic population: Worcester Area Trial for Counseling in Hyperlipidemia (WATCH). Arch Inter Med. 1999;159(7):725-731. doi:10.1001/archinte.159.7.725

25. Wadden TA, Butryn ML, Hong PS, Tsai AG. Behavioral treatment of obesity in patients encountered in primary care settings: a systematic review. JAMA. 2014;312(17):1779-1791. doi:10.1001/jama.2014.14173

26. Hartmann-Boyce J, Johns DJ, Jebb SA, Summerbell C, Aveyard P. Behavioural weight management review group. Behavioural weight management programmes for adults assessed by trials conducted in everyday contexts: systematic review and meta-analysis. Obes Rev. 2014;15(11):920-932. doi:10.1111/obr.12220

27. Armenta Guirado BI, Díaz Zavala RG, MEF VJ, Quizán Plata T. Manejo de la obesidad en el primer nivel de atención con un programa intensivo de cambio de estilo de vida. Nutr Hosp. 2015;32 (4):1526-1534. doi:10.3305/nh.2015.32.4.9366

28. Tsai AG, Remmert JE, Butryn ML, Wadden TA. Treatment of obesity in primary care. Med Clin North Am. 2018;102(1):35-47. doi:10.1016/j.mcna.2017.08.005
29. Centro Nacional de Programas Preventivos y Control de Enfermedades [homepage on the Internet]. Declaratorias de emergencia. México: CENAPRECE; 2018. Available from: http://www.cenaprece.salud. gob.mx/programas/interior/emergencias/declaratorias_emergencia. html. Accessed March 08, 2019.

30. Villalpando S, de la Cruz V, Rojas R, et al. Prevalence and distribution of type 2 diabetes mellitus in Mexican adult population: a probabilistic survey. Salud Publica Mex. 2010;52(Suppl 1): S19-S26.

31. Barquera S, Campos I, Rivera JA. Mexico attempts to tackle obesity: the process, results, push backs and future challenges. Obes Rev. 2013;14(Suppl 2):69-78. doi:10.1111/obr.12096

32. Perlroth $\mathrm{N}$ [homepage on the Internet]. Spyware's odd targets: backers of Mexico's soda tax. New York Times. 2017 February, 11. Available from: https://www.nytimes.com/2017/02/11/technology/ hack-mexico-soda-tax-advocates.html. Accessed March 08, 2019.

33. UK Health Forum. Public Health and the Food and Drinks Industry: the Governance and Ethics of Interaction. Lessons from Research, Policy and Practice. London: UKHF; 2018.

34. López-Gatell H [homepage on the internet]. Acabarán con injerencia de la IP en etiquetados de bebidas y alimentos. La Jornada. Ciudad de México; 2019. Available from: https://www.jornada.com.mx/2019/ 03/05/sociedad/031n1soc. Accessed March 08, 2019.

35. Wadden TA, Webb VL, Moran CH, Bailer BA. Lifestyle modification for obesity. Circulation. 2012;125(9):1157-1170. doi:10.1161/ CIRCULATIONAHA.111.039453

36. Levy RL, Finch E, Crowell MD, Talley NJ, Jeffery RW. Behavioral intervention for the treatment of obesity: strategies and effectiveness data. Am J Gastroenterol. 2007;102(10):2314-2321. doi:10.1111/ j.1572-0241.2007.01342.x

37. Williamson DA. Fifty years of behavioral/lifestyle interventions for overweight and obesity: where have we been and where are we going? Obesity (Silver Spring). 2017;25(11):1867-1875. doi:10.1002/oby.21914

38. Knowler WC, Barrett-Connor E, Fowler SE, et al. Reduction in the incidence of type 2 diabetes with lifestyle intervention or metformin. N Engl J Med. 2002;346(6):393-403. doi:10.1056/NEJMoa012512

39. Look AHEAD Research Group. Eight-year weight losses with an intensive lifestyle intervention: the look AHEAD study. Obesity (Silver Spring). 2014;22(1):5-13. doi:10.1002/oby.20662.

40. Pi-Sunyer X. The look AHEAD trial: a review and discussion of its outcomes. Curr Nutr Rep. 2014;3(4):387-391. doi:10.1007/s13668014-0099-x

41. The Look AHEAD Research Group. Cardiovascular effects of intensive lifestyle intervention in type 2 diabetes. $N$ Engl J Med. 2013;369 (2):145-154. doi:10.1056/NEJMoa1212914.

42. The Look AHEAD Research Group; Gregg E, Jakicic J, et al. Association of the magnitude of weight loss and changes in physical fitness with long-term cardiovascular disease outcomes in overweight or obese people with type 2 diabetes: a post-hoc analysis of the Look AHEAD randomized clinical trial. Lancet Diabetes Endocrinol. 2016;4(11):913-921. doi:10.1016/S2213-8587(16)30162-0.

43. The Diabetes Prevention Program Research Group. The Diabetes Prevention Program (DPP): description of lifestyle intervention. Diabetes Care. 2002;25(12):2165-2171. doi:10.2337/diacare.25.12.2165.

44. The Look AHEAD Research Group; Wadden TA, West DS, et al. The look AHEAD study: a description of the lifestyle intervention and the evidence supporting it. Obesity (Silver Spring). 2006;14(5):737-752. doi:10.1038/oby.2006.84.

45. Garfield SA, Malozowski S, Chin MH, et al. Considerations for diabetes translational research in real-world settings. Diabetes Care. 2003;26(9):2670-2674. doi:10.2337/diacare.26.9.2670

46. Ali MK, Echouffo-Tcheugui JB, Williamson DF. How effective were lifestyle interventions in real-world settings that were modeled on the diabetes prevention program? Health Aff (Millwood). 2012;31(1):6775. doi:10.1377/hlthaff.2011.1009 
47. Diabetes Prevention Program Research Group. The 10-year cost-effectiveness of lifestyle intervention or metformin for diabetes prevention. Diabetes Care. 2012;35(4):723-730. doi:10.2337/dc11-1468.

48. Ackermann RT, Marrero DG. Adapting the diabetes prevention program lifestyle intervention for delivery in the community. Diabetes Educ. 2007;33(1):69-78. doi:10.1177/0145721706297743

49. Ackermann RT, Finch EA, Brizendine E, Zhou H, Marrero DG. Translating the diabetes prevention program into the community. The DEPLOY pilot study. Am J Prev Med. 2008;35(4):357-363. doi:10.1016/j.amepre.2008.06.035

50. Albright AL, Gregg EW. Preventing type 2 diabetes in communities across the U.S: the national diabetes prevention program. Am J Prev Med. 2013;44(4 Suppl 4):S346-S351. doi:10.1016/j.amepre.2012.12.009

51. Mensa-Wilmot Y, Bowen SA, Rutledge S, et al. Early results of states' efforts to support, scale, and sustain the national diabetes prevention program. Prev Chronic Dis. 2017;14:E130. doi:10.5888/pcd14.170478

52. Centers for Disease Control and Prevention [homepage on the Internet]. National Diabetes Prevention. United States: Centers for Disease Control and Prevention; 2019. Available from: https://www.cdc.gov/diabetes/pre vention/index.html. Accessed March 08, 2019.

53. Jensen MD, Ryan DH, Apovian CM, et al. 2013 AHA/ACC/TOS guideline for the management of overweight and obesity in adults. Circulation. 2014;129(25 Suppl 2):S102-S138. doi:10.1161/01. cir.0000437739.71477.ee

54. US Preventive Services. Task force. Behavioral weight loss interventions to prevent obesity-related morbidity and mortality in adults: US preventive services task force recommendation statement. JAMA. 2018;320(11):1163-1171. doi:10.1001/jama.2018.13022.

55. LeBlanc ES, O’Connor E, Whitlock EP, Patnode CD, Kapka T. Effectiveness of primary care-relevant treatments for obesity in adults: a systematic evidence review for the U.S. preventive services task force. Ann Intern Med. 2011;155(7):434-447. doi:10.7326/00034819-155-7-201110040-00006

56. Treviño RP, Piña C, Fuentes JC, Nuñez M. Evaluation of medicare's intensive behavioral therapy for obesity: the bienestar experience. $\mathrm{Am}$ J Prev Med. 2018;54(4):497-502. doi:10.1016/j.amepre.2018.01.018

57. Counterweight Project Team. Evaluation of the counterweight programme for obesity management in primary care: a starting point for continuous improvement. Br J Gen Pract. 2008;58(553):548-5559. doi:10.3399/bjgp08X319710.

58. Trueman P, Haynes SM, Felicity LG, et al. Long-term cost-effectiveness of weight management in primary care. Int J Clin Pract. 2010;64(6):775-783. doi:10.1111/j.1742-1241.2010.02349.x

59. Devries S, Dalen JE, Eisenberg DM, et al. A deficiency of nutrition education in medical training. Am J Med. 2014;127(9):804-806. doi:10.1016/j.amjmed.2014.04.003

60. Barnard ND. Ignorance of nutrition is no longer defensible. JAMA Intern Med. 2019. doi:10.1001/jamainternmed.2019.2273

61. Dietz WH, Baur LA, Hall K, et al. Management of obesity: improvement of health-care training and systems for prevention and care. Lancet 2015;385(9986):2521-2533. doi:10.1016/S0140-6736(14)61748-7
62. Vetter ML, Herring SJ, Sood M, Shah NR, Kalet AL. What do resident physicians know about nutrition? An evaluation of attitudes, self-perceived proficiency and knowledge. J Am Coll Nutr. 2008;27 (2):287-298

63. Adams KM, Kohlmeier M, Zeisel SH. Nutrition education in U.S medical schools: latest update of a national survey. Acad Med. 2010;85(9):1537-1542. doi:10.1097/ACM.0b013e3181eab71b

64. Møller G, Andersen HK, Snorgaard O. A systematic review and meta-analysis of nutrition therapy compared with dietary advice in patients with type 2 diabetes. Am J Clin Nutr. 2017;106(6):13941400. doi:10.3945/ajcn.116.139626

65. Ashley JM, St Jeor ST, Schrage JP, et al. Weight control in the physician's office. Arch Intern Med. 2001;161(13):1599-1604.

66. Delahanty LM, Dalton KM, Porneala B, et al. Improving diabetes outcomes through lifestyle change - A randomized controlled trial. Obesity (Silver Spring). 2015;23(9):1792-1799. doi:10.1002/oby.21172

67. Ma J, Yank V, Xiao L, et al. Translating the diabetes prevention program lifestyle intervention for weight loss into primary care: a randomized trial. JAMA Intern Med. 2013;173(2):113-121. doi:10.1001/2013.jamainternmed.987

68. Appel LJ, Clark JM, Yeh H-C, et al. Comparative effectiveness of weight-loss interventions in clinical practice. $N$ Engl J Med. 2011;365 (21):1959-1968. doi:10.1056/NEJMoa1108660

69. Ahern AL, Wheeler GM, Aveyard P, et al. Extended and standard duration weight-loss programme referrals for adults in primary care (WRAP): a randomised controlled trial. Lancet. 2017;389 (10085):2214-2225. doi:10.1016/S0140-6736(17)30647-5

70. Ahern AL, Aveyard PN, Halford JCG, et al. Weight loss referrals for adults in primary care (WRAP): protocol for a multi-centre randomised controlled trial comparing the clinical and cost-effectiveness of primary care referral to a commercial weight loss provider for 12 weeks, referral for 52 weeks, and a brief self-help intervention [ISRCTN82857232]. BMC Public Health. 2014;14:620.

71. Díaz-Zavala RG, Armenta-Guirado B, Martínez-Contreras TDJ, et al. Translational study of obesity management using the diabetes prevention program "Group Lifestyle Balance" in primary care clinics and public hospitals from Mexico: study protocol. Rev Esp Nutr Hum Diet. 2017;21:369-383. doi:10.14306/renhyd.21.4.391

72. Colchero MA, Popkin BM, Rivera JA, Ng SW. Beverage purchases from stores in Mexico under the excise tax on sugar sweetened beverages: observational study. BMJ. 2016;352:h6704. doi:10.1136/bmj.i1717

73. Rivera-Dommarco JA, Colchero M, Fuentes ML, et al. La obesidad en México. Estado de la política pública y recomendaciones para su prevención y control. Cuernavaca: Instituto Nacional de Salud Pública, ed; 2018.

74. Barquera S, White M. Treating obesity seriously in Mexico: realizing, much too late, action must be immediate. Obesity (Silver Spring). 2018;26(10):1530-1531. doi:10.1002/oby.22296

Diabetes, Metabolic Syndrome and Obesity: Targets and Therapy

Dovepress

\section{Publish your work in this journal}

Diabetes, Metabolic Syndrome and Obesity: Targets and Therapy is an international, peer-reviewed open-access journal committed to the rapid publication of the latest laboratory and clinical findings in the fields of diabetes, metabolic syndrome and obesity research. Original research, review, case reports, hypothesis formation, expert opinion and commentaries are all considered for publication. The manuscript management system is completely online and includes a very quick and fair peer-review system, which is all easy to use. Visit http://www.dovepress.com/testimonials.php to read real quotes from published authors. 